\title{
Electric vehicle use and energy consumption based on real- world electric vehicle fleet trip and charge data and its impact on existing EV research models
}

\author{
De Cauwer C. ${ }^{1}$, Maarten M. ${ }^{1}$, Heyvaert S. ${ }^{1}$ Coosemans T. ${ }^{1}$, Van Mierlo J. ${ }^{1}$ \\ ${ }^{l}$ Vrije Universiteit Brussel, Pleinlaan 2-B-1050 Brussels, cedric.de.cauwer@vub.ac.be
}

\begin{abstract}
This paper presents the results of an analysis of real-world trip and charge data from an electric vehicle (EV) fleet, deployed in the Flanders' Living Labs. The Flanders' Living Labs are life test environments for electric mobility in which companies and organizations can test innovative technologies, products, services and concept and consists of 5 EV platforms, each differing in technology, scope, size and usage [1]. These platforms have produced a large amount of data on numerous topics in the field of electric mobility. This paper focuses on available trip and charge data to analyze user behavior and EV energy consumption. It presents descriptive statistics of trips and charges, as well as EV energy consumption. By obtaining these results from real-world data on electrical vehicles, the authors are able to update statistical figures of fleet use and energy consumption, specifically for electric vehicles. Using specific electric vehicle figures has consequences on the results of (calculation) models of other research branches in electric mobility like total cost of ownership (TCO), Life Cycle Assessment (LCA), etc. The potential effect of these real-world data on these models is investigated and recommendations regarding the use of these data are formulated.
\end{abstract}

Keywords: list 3-5 Living lab, EV, electric vehicle fleet, energy consumption

\section{Introduction}

Under the pressure of current environmental challenges, with climate change as protagonist, a renewed interest in electric vehicles (EV) emerged because of its potential for the reduction of GHG emissions and local emissions [2]. The introduction of electric vehicles, however, contains a number of challenges because of its current performance limitations and technological differences which requires infrastructural changes, as well as behavioral and attitudinal changes from users. These challenges are the subject of new or established research domains in which potential technical or operational improvements, environmental impact and cost assessments, consumer and market responses etc. are investigated. Because of the early stage of the EV market penetration, these studies and models are based on assumptions and rely heavily on the available, often still limited, data. Altering assumptions, the level of simplification and the available data to construct the model may alter the outcome of the model or estimation and its interpretation. To obtain realistic and real-world data on electric mobility, a number of 'Living Labs' have been deployed over Europe. The Flanders' Living Lab electric Vehicle is a life test environments for electric mobility in which companies and organizations can test innovative technologies, products, services and concepts and consists of $5 \mathrm{EV}$ platforms, each differing in technology, scope, size and usage [1][3]. These platforms have produced a large amount of data on the use of electric vehicles and EV infrastructure which can be valuable for some of these research topics. This paper presents an overview of aggregated real-world data which has been identified as input data for models of multiple research topics in the domains of electric vehicles.

\section{Data availability and reliability}

The data which is used for this paper was generated by vehicles from the EVA and iMove 
platform of the Flanders Living Lab Electric Vehicles. This section gives an overview of the type, nature and amount of the data used to obtain the results.

\subsection{GPS data}

The EVA and iMove platform generated GPS recorded data of a mixed EV and Plug-in Hybrid Vehicle (PHEV) fleet. This data was looked at for the period of 2013-2014. The EVA platform had a phased roll-out of vehicles and infrastructure, which makes the amount of available data per vehicle specific. So in the case of the EVA fleet, not all vehicles provided data for a full year, in which case the monthly average was extrapolated if a minimum of 7 months was available.

\subsection{Vehicle measurements}

Additionally, energy consumption measurements have been performed on a Nissan Leaf part of the EVA project, by means of a CAN logger which registered battery current and voltage on a $1 \mathrm{~Hz}$ frequency for the duration of two years. Supplementary measurements have been performed to obtain tank-to-wheel energy consumptions for this vehicle using 43 measured charging sessions spread over the course of 1 year at 4 different stages of energy conversion: AC grid measurement before the charging station (EVSE), AC measurement after the charging station, DC measurement after the AC/DC converter and a DC measurement from the battery during use. These particular charging sessions recharged to a full state-of-charge ( $\mathrm{SoC}$ ) after various levels of depletion from a full $\mathrm{SoC}$ to be able to link all energy conversion stages.

\subsection{Charging station data}

The iMove platform also registered charging data from the platform charging infrastructure. By linking the charging data with the trip data, additional grid-to-wheel energy consumption for a part of the iMove fleet and monitoring period could be attained. A particular test period in iMove consisted of appointing one vehicle to one specific driver, and installing home mode 3 charging infrastructure. These vehicles were then only equipped with a mode 3 charging cable. Because of the particular status of public infrastructure at that point, it was difficult to charge on public infrastructure with mode 3 cables, and therefor unlikely the test population charged in a none iMove mode 3 charging infrastructure. The charging station identified the vehicle by means of a charging pass linked to the vehicles license plate. Thus a one-on-one relation between the trips and the charges can be done for this particular data. Using this method, the result is sensitive to gaps in the data (such as missing trips or charges on non-iMove infrastructure) and misuse (such as misidentification by for example lending charge passes). For this reason the data was heavily filtered and only parts with a good reliability were kept, which decreases the amount of data significantly. This test period consisted of 49 vehicles of 3 vehicle types (Renault Kangoo, Renault Fluence, Peugeot Ion) driven each by 4 different drivers, each over a period of around 2 months. After filtering and aggregation it left 67 individual driver periods of around 2 months.

\section{3 'Real-world' EV 'Energy consumption'}

Real-world data has the advantage of being closer to the reality as it is based on measurements and observations of real use. As the electric vehicle is still in an introduction phase, large real-world data is only being generated gradually and academic knowledge largely depends on trials and living labs. Moreover, as with conventional vehicles, standard test cycles such as NEDC and other are still being used to characterize the vehicles. Although it has value on a comparison basis, it is widely accepted that these cycles do not reflect real-world driving [4] [5]. Despite numerous efforts to develop more realistic drive cycles [5][6][7][8], these are not yet applied for the characterization of EVs and do not necessarily apply to the use of electric vehicles as, because of it specific differences with conventional technology, the EV driving behaviour can be different than what is observed from the available historic data of conventional vehicles. Additionally, the use of the parameter 'energy consumption' is not always clear to the reader, even if so to the author. When describing energy consumption, it is important to specify the scope of the energy supply chain and the measurement method. Because of energy losses from the energy drawn from the plug to the energy in the battery, distinction has been made by specifying DC or AC energy consumption, referring to the energy consumption measured at the plug (before the $\mathrm{AC} / \mathrm{DC}$ conversion) and drawn from the battery respectively. In this paper, this corresponds to a plug-to-wheel and battery-to-wheel energy 
consumption. Energy consumption as measured on a test cycle is therefore a plug-to-wheel consumption as it measures the energy necessary for recharging at the plug. As this is the scope of energy consumption related to the vehicle, it corresponds to the definition of tank-to-wheel scope, also used for fuel consumption of conventional vehicles, and is therefore the terminology consistently used in LCA studies [9]. The energy losses in the electric vehicle supply equipment (EVSE) are part of the grid losses and are therefore part of the well-to-tank scope.

The complexity of the matter even increases when considering battery efficiency. Some authors only consider resistive losses for the battery and consider additional losses for cell balancing and other battery management functions performed by the battery management system (BMS) as energy consumption of auxiliaries[10], altering the values for battery efficiency and battery-to-wheel energy consumption compared to when BMS losses are included as battery losses. Figure 1 gives a schematic overview of the energy scopes of the energy supply (in green), and how that relates to the energy consumption of an electric vehicle. The bottom part can be interpreted as sequential energy conversion steps (from left to right), starting with a 100 energy units at the AC side before the electric EVSE, and ending with 52 energy units usable energy for traction, so a tank-to-wheel scope plus EVSE losses. The battery efficiency in this figure was defined as the ratio of the total amount of energy drawn from the battery to the total amount of energy going into the battery (charge energy and energy from regenerative braking).

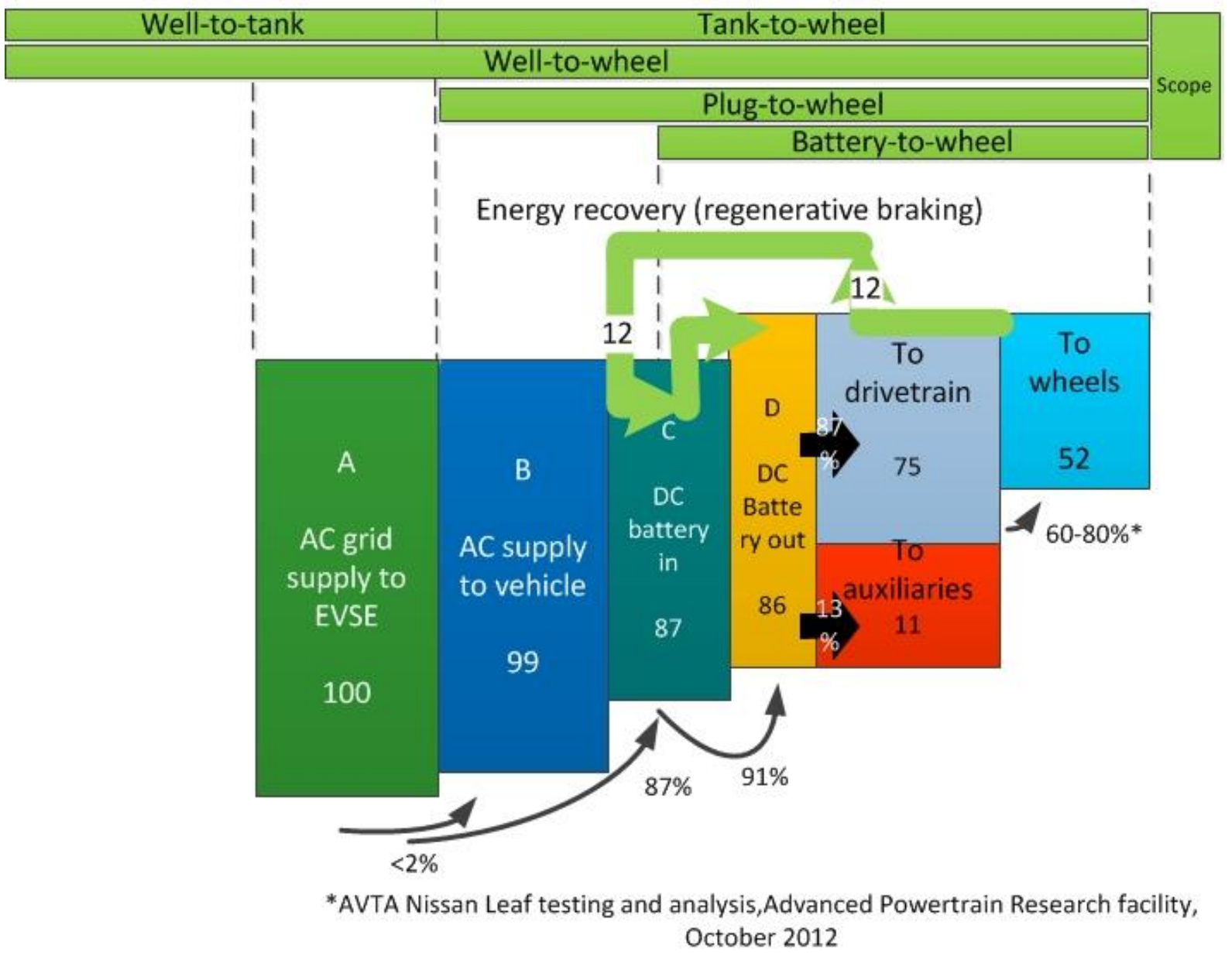

Figure 1 Grid-to-wheel energy distribution measured on 1 Nissan Leaf and its relation to the energy consumption scope 


\section{Research topics to benefit from real-world data}

Depending on the research topic in the domain of electric vehicles, a different scope of the energy supply chain is targeted, and definitions of energy consumption may change. In this section a number of research topics are introduced and investigated how they rely on EV use and energy consumption and how they might benefit from real-world data and thus more realistic input data for their calculations.

Life cycle assessment (LCA) for vehicles calculates the environmental impact from cradleto-grave, including the mining of materials, the production of the car, the energy consumption and the end-of-life treatment. The total energy consumption is analysed using a well-to-wheel framework, taking into account the consumption in the car (tank-to-wheel) and the production of the fuel or electricity starting from the primary energy resources (well-to-tank). For EVs, the tank-to-wheel scope corresponds to a plug-towheel scope in Figure 1, as discussed above. For the tank-to-wheel consumptions of EVs, LCA studies typically use the tank-to-wheel consumption as reported by the manufacturer and which is based on NEDC or other cycle tests [2][11][12]. Generally, the NEDC measurements are underestimating the energy consumption and real-world data improves the level of correctness in LCA studies. Furthermore, eco-design strategies incorporating detailed energy losses in the drivetrain can augment the overall environmental performance of an electric car. Coupling real-time charging patterns with timely environmental impacts of producing electricity brings a new environmental optimization potential. For instance, off-peak charging of electric vehicles brings further environmental improvements. An hourly environmental impact assessment of electricity production can be found in [13]. Similarly to most LCA studies, total cost of ownership (TCO) does not yet use real-world data but uses statistical data on historic use of conventional vehicles and estimates for the use of EVs [12]. [12] shows two major assumptions are made to calculate the TCO for EVs. The yearly driven distance is the same as for an average Belgian consumer and secondly the maintenance cost is set to $60 \%$ of a conventional vehicle.

The range of the electric vehicle is dependent on the energy available in the battery and the energy consumption. Thus accurate $\mathrm{SoC}$ and $\mathrm{SoH}$ estimation and energy consumption estimation are needed in order to have accurate range estimation. As such, it is done on the battery-to-wheel scale and is independent of energy losses prior to entering the battery. Another research topic that could use range estimation for EVs is vehicle routing problem (VRP). A vehicle routing problem (VRP) generally strives for a cost optimal solution for a delivery problem. Introducing $\mathrm{EVs}$ in the vehicle fleet for delivery service is very new, and so is the assessment of its feasibility and cost impact [14]. Introducing EVs in its fleet changes the boundary conditions of the problem because of different performances of EVs, i.e. its range and cost per $\mathrm{km}$. [15] introduced EVs in a case study VRP, with the boundary of range restrictions. The basic linear range model itself was calculated based on real-world (battery-to-wheel) consumption data. To improve the VRP algorithm with EVs, accurate range estimation is needed for the feasibility (so energy consumption on the battery-to-wheel scope), and running costs based on real-world consumptions (so energy consumption on tank-to-wheel) in order to have a more realistic outcome. Important to note is that ultimately the consumer as an interested party is generally mainly interested in the cost (so plug-to-wheel), range (battery-towheel) and only in a limited amount the environmental impact (so well-to-wheel)[17][16].

\section{Results}

\subsection{Use characterization}

In this section a series of aggregated results will be presented to give an overview of the average use of the different fleets. Table 1 gives an overview of average considered data for the iMOVE and EVA fleet for both the EVs and PHEVs. Additionally, the Nissan Leaf (which has detailed information) was added to the table to position that particular vehicle among the population. 
Table 1 Overview of yearly averaged aggregated data for iMOVE and EVA fleets, for both EVs and PHEVs

\begin{tabular}{|c|c|c|c|c|c|}
\hline & EVA EV & EVA PHEV & iMOVE EV & iMOVE PHEV & VUB Leaf \\
\hline $\begin{array}{l}\text { Number vehicle years } \\
\text { (vehicles * years) }\end{array}$ & 48 & 10 & 172 & 18 & 2 \\
\hline Distance monitored (km) & 259.621 & 109.174 & 846.249 & 302.367 & 27.026 \\
\hline $\begin{array}{l}\text { Average total days } \\
\text { monitored per year (days) }\end{array}$ & 335 & 326 & 322 & 339 & 365 \\
\hline $\begin{array}{l}\text { Average number of days } \\
\text { active (days) }\end{array}$ & 165 & 182 & 146 & 193 & 265 \\
\hline Active days rate (\%) & 49 & 56 & 45 & 57 & 73 \\
\hline Average daily distance (km) & 28 & 61 & 29 & 73 & 48 \\
\hline Average yearly distance $(\mathrm{km})$ & 5.409 & 13.248 & 5.568 & $\begin{array}{c}11.709 \\
(13.099)\end{array}$ & 13.513 \\
\hline
\end{tabular}

Table 1 shows that the available data was higher for the iMOVE than EVA fleet, due to the reasons discussed in section 2.1. Instead of presenting the data as aggregated data per vehicle, the data are presented in vehicle years, which is the individual vehicle times the number of years it has been used. Because during the course of the project the vehicles changed in between private users or were used as pool car, this approach is justified. The active days rate is defined as the number of days used divided by the number of days monitored. The data comprises 252 vehicle years of position data. Without making further distinction of any vehicle user characteristics, ANOVA analysis shows the average yearly driven distance of the EV fleet are very significantly $(p<0.001)$ lower than the PHEV fleets average early distance. The use of the individual vehicles varied strongly. The

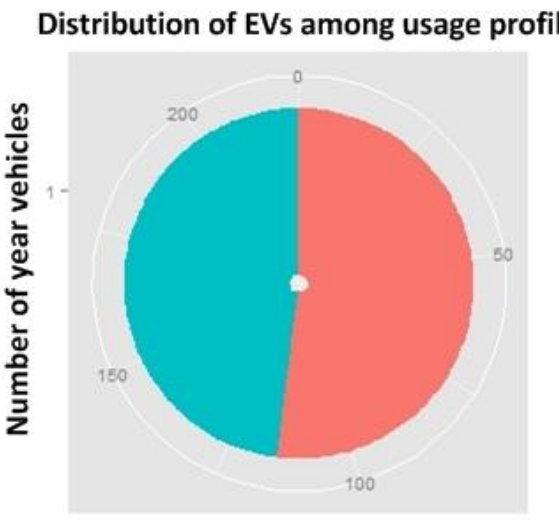

purpose each vehicle fulfilled in the fleet varies: service vehicle in municipalities, pool car in municipalities, pool car in businesses, company car or a car used as if as privately owned in municipalities. To be able to have a sufficiently large population in each of the categories, only two user profile categories were defined. A "pool" car category, comprising all cars that are shared between employees of municipalities or businesses and are not dedicated to a specific person for a certain amount of time, and a category comprising all vehicles used as if privately owned and that were dedicated to 1 person for a certain amount of time, which is called "personal". The distribution of these two usage profiles categories is presented in Figure 2 for both the combined EV fleet and the combined PHEV fleet separately.

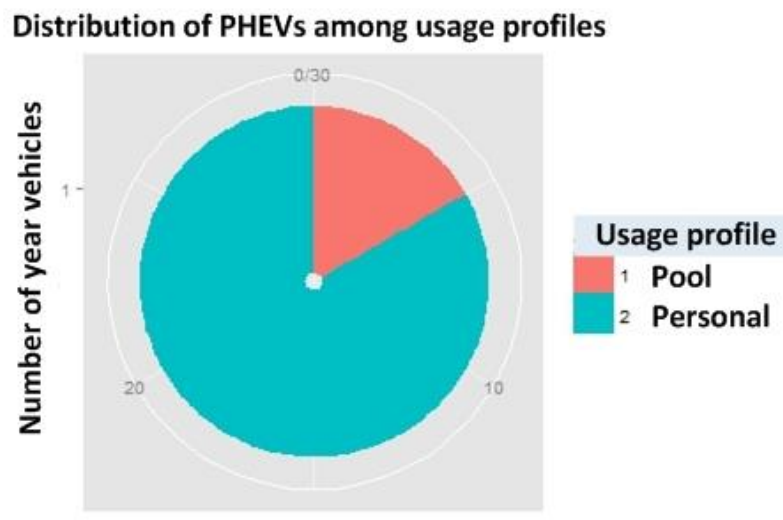

Figure 2 Distribution of the usage profile (pool car or car for personal use) for the combined EV fleet and PHEV fleet 
The distribution of vehicles among both categories is close to equal for the EVs, whereas the PHEVs used as pool car is less than a quarter of the PHEV population. It has to be said that especially within the pool category, further subdivision of the category is possible. For example, separating the vehicles which allowed only purely professional use from those which allowed personal use (ex. weekends), could have a significant impact on the driven distance. Because of the difficulties for verification, it was chosen not to do so. In both user EV and PHEV and categories, a few vehicle years showed very low, unrealistic values for the yearly driven distance (example: 1 PHEV vehicle with a $70 \mathrm{~km}$ yearly driven distance, $1 \mathrm{EV}$ with $20 \mathrm{~km}$ yearly driven distance and 6 active days) and were eliminated from the population. Additionally , eliminating all vehicle years under $1000 \mathrm{~km}$ for the PHEVs in the iMove population, which are also likely to be not realistic, leaves 24 (of 28) vehicle years and increases the minimum value to $2517 \mathrm{~km}$ and the mean to $13156 \mathrm{~km}$. These 4 eliminated PHEVs were part of the iMove fleet. Eliminating them from that iMOVE PHEV population in Table 2 gives a mean of 13099 , which is the number indicated between brackets. Because of the lower average for the EVs and their different spread, it was chosen not to do a similar elimination for the EV category. Nevertheless, these low values influence the average value and are possibly not representative for the population. As an example it was observed that in a case where a conventional vehicle was present as an alternative for the use of a pool car, it was selected in favour of the EV.

\subsection{Yearly driven distance}

Although Table 1 already presented averaged results for the yearly driven distance of the fleets, in this section more detailed results on the yearly driven distance are presented. The distribution of the yearly driven distance per vehicle type (EV or PHEV) and user profile category for the entire fleet is given in Figure 3. As said in section 5.1, the average of the yearly driven distance of the PHEVs is significantly higher and more than twice the one of EVs. Additionally, the vehicle categories' average yearly driven distance of 5.508 and 13156 (filtered, see section 5.1) for the EVs and PHEVs respectively, are below the Belgian average of $15.000 \mathrm{~km}$ [12]. The spread for the EV's yearly driven distances, combined for both user categories, results in only 4 vehicle years out of the 223 vehicle years to be over this yearly Belgian average of $15.000 \mathrm{~km}$. Separating the data by their user profile category gives more differentiated for the EVs. The figure shows the yearly driven distance increases very significantly (ANOVA, p<0.001) for the EVs used as if privately owned $(6.952 \mathrm{~km})$ compared the pool EVs (4214km).

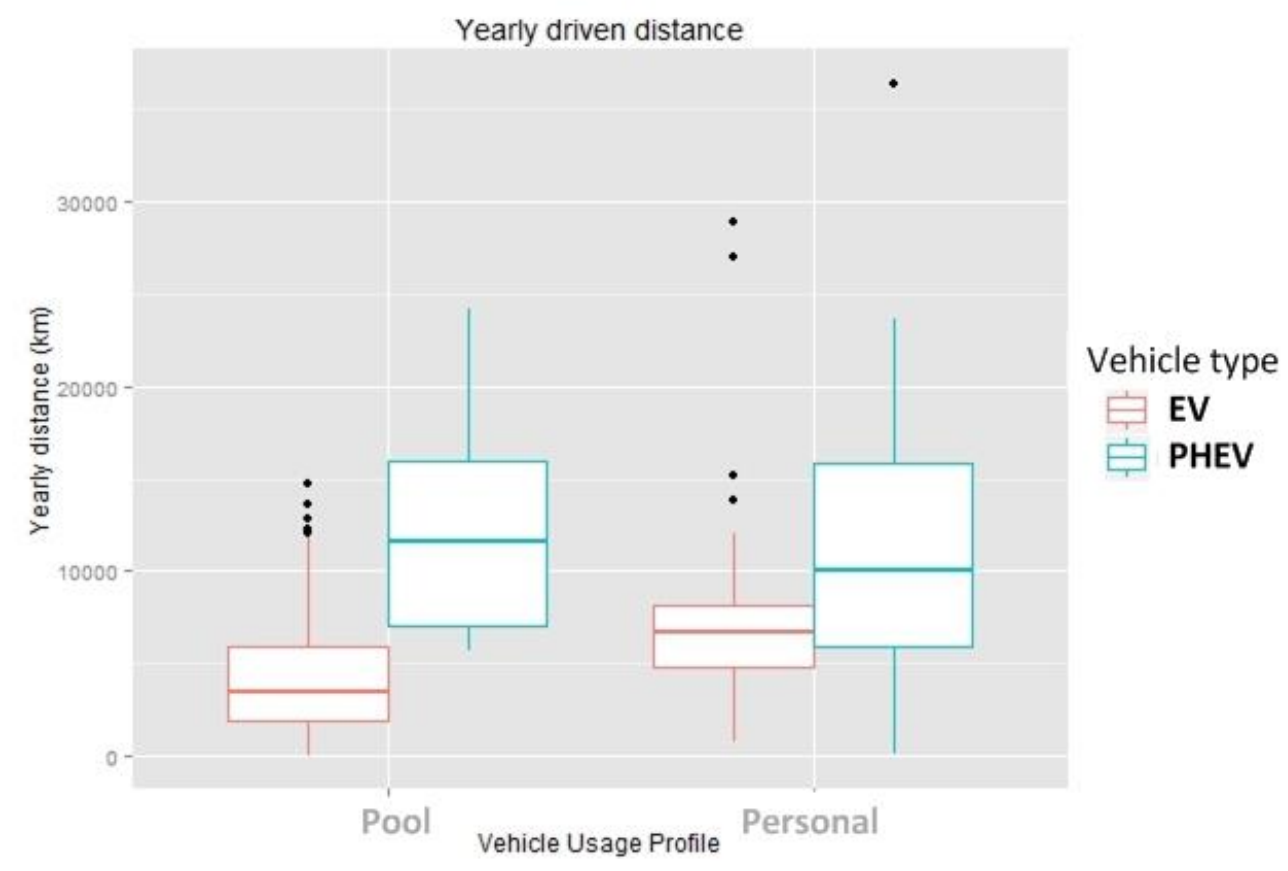

Figure 3 Boxplot of the yearly driven distance per vehicle type and vehicle user profile 


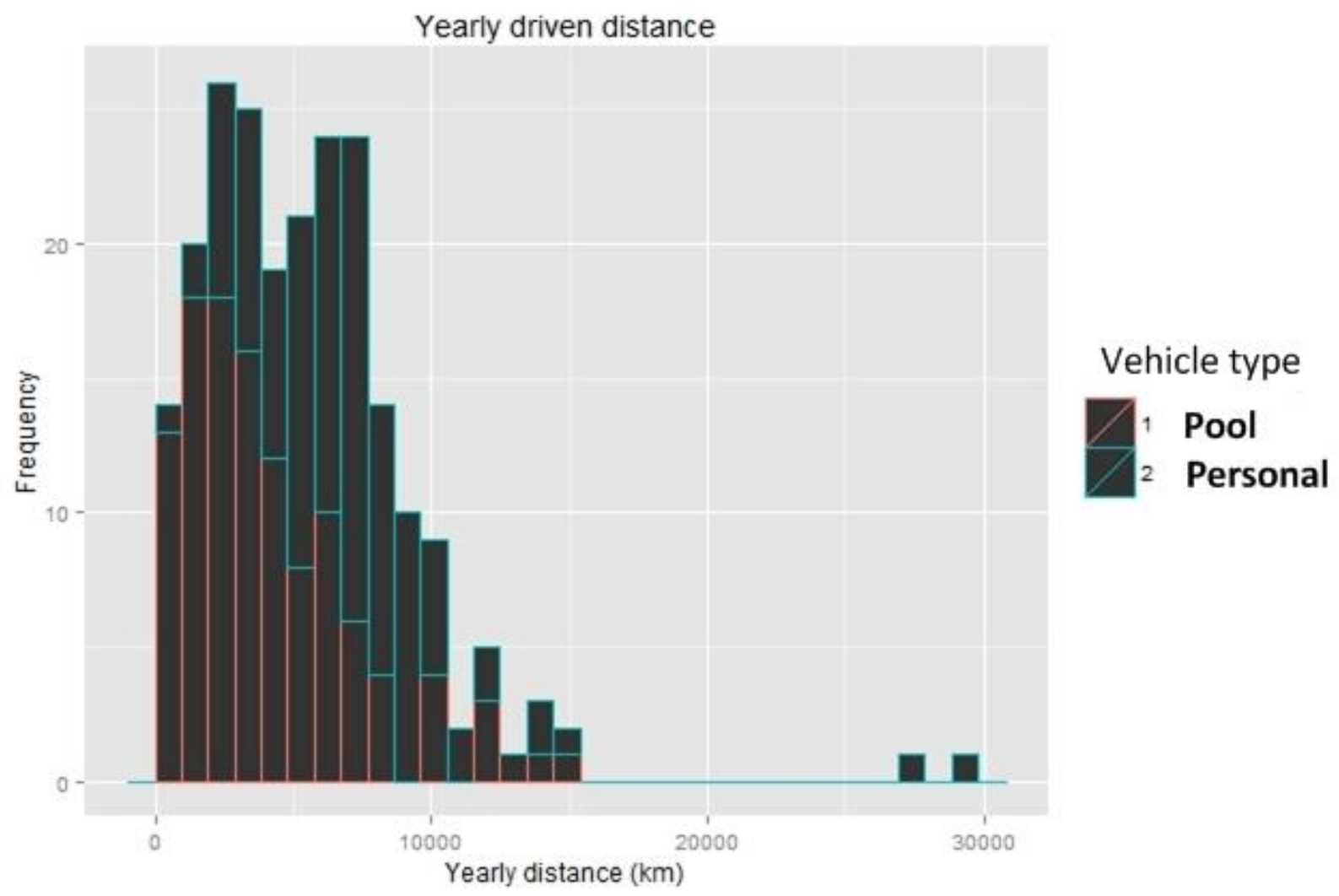

Figure 4 Histogram of the yearly driven distances for all EVs and their contribution per user profile category

Figure 4, which depicts a histogram of the distribution of yearly driven distances for all EVs and the contribution per user profile category, shows how the distribution of the personal category shifts toward higher values. Combining both distributions results in a near uniform distribution. The same shift of the yearly driven distance' average and distribution cannot be observed for the PHEVs, where only the spread is different per user profile category.

However, as discussed in section 2.1, these populations and their use of the vehicles has boundary conditions and should therefore not blindly be compared to a Belgian average. Distinction has already been made and observed between the pool and personal vehicles. Yet, further limitations such as company policies and use restrictions, the individual user inexperience (and frequent driver change), available infrastructure, specific (utility) use or (in case of a pool car) the availability of alternatives. A good example is the university EV which, with $13.000 \mathrm{~km}$ yearly, is an outlier in the pool category, but had no company restrictions (was allowed for personal use), extensive charging infrastructure at the university and EV experts as drivers. On the other extreme, a pool EV in a private company showed $700 \mathrm{~km}$ yearly for two consecutive years but was used for particular trips and had conventional vehicles as alternatives. So further research has to be done to further differentiate the user categories and map the influences of the boundaries on the averages of the yearly driven distances. This influence of boundary conditions is also highlighted by the difference between the yearly driven distances for the PHEVs, which can be considered to have no performance restrictions compared to conventional vehicles, in the personal category $(13.000 \mathrm{~km})$ here and the company car Belgian average of $25.000 \mathrm{~km}$ presented in [18]. And in contrast, the two most extreme outliers of the EV personal category, visible in Figure 3 and Figure 4 are right within that $25.000 \mathrm{~km}$ region and are reported to be done by one user using the vehicle to commute each day, almost depleting it at each time. 


\subsection{Energy results}

In this section the energy consumptions of the vehicle fleets are analysed. More in particular the iMove fleet energy consumption and VUB vehicle consumption. It comprised in total of 5 vehicle types: Citroën C-Zero, Peugeot iON, Renault Kangoo ZE, Renault Fluence and Nissan Leaf. Because of their identical design, the iON and C-Zero are considered as 1 type. Except for the Nissan Leaf, which is a pool-car, all vehicles have the user profile Personal. Table 2 gives an overview of the measured and NEDC tank-towheel-consumptions of these vehicles, the amount of data (in terms of driven distance) over which the measurements are taken and the number of vehicles that contributed to the measurements, which is expressed in vehicle persons (except for the Nissan Leaf). A vehicle person is here defined as an individual vehicle times the number of persons who were dedicated to it for a certain time (see section2). Although the Nissan Leaf belongs to a different user profile, it is included in Table 2 as this difference is not important for the aggregated results presented here and it did provide largely sufficient data. Table 2 shows real-world consumption is around $30-60 \%$ higher compared to the NEDC value. The $0.181 \mathrm{kWh}_{\mathrm{AC}}$ for the $\mathrm{iON}$ is similar to the value real- world consumption measured in [10] and lies between WLTC-cycle and CADC-cycle consumption measured in [19]. The real-world value for the Kangoo $\mathrm{ZE}$ consumption here is close to the $0.222 \mathrm{kWh} / \mathrm{km}$ value for the WLTC cycle presented in [19]. The NEDC measured consumption values in [19] for both vehicles, however, are far above manufacturer value as well. Because of the nature of the data (see section 2.3), unrealistic data have been filtered by means of upper and lower limits for the consumption. Using this approach, the result is especially sensitive for systematic errors, which are difficult to detect. Especially the results for the Renault Kangoo ZE and Fluence ZE were sensitive to a change of the upper limit.

Additionally, the presented energy consumption values here are total averages, and do not make a differentiation between consumptions using potential influential parameters such as temperature, driving style, road topology etc. Large variation might exist taking into account these different parameters.

Table 2 Overview of the measured and NEDC grid-to-wheel consumption per vehicle

\begin{tabular}{lcccc}
\hline & Vehicle type 1 & $\begin{array}{c}\text { Vehicle } \\
\text { type 2 }\end{array}$ & $\begin{array}{c}\text { Vehicle } \\
\text { type 3 }\end{array}$ & $\begin{array}{c}\text { Vehicle } \\
\text { type 4 }\end{array}$ \\
\hline Model & $\begin{array}{c}\text { Citroën C- } \\
\text { zero/ } \\
\text { Peugeot iOn } \\
\text { 11787 }\end{array}$ & $\begin{array}{c}\text { Renault } \\
\text { Kangoo ZE }\end{array}$ & $\begin{array}{l}\text { Renault } \\
\text { Fluence }\end{array}$ & Nissan Leaf \\
\hline Distance measured (km) & 0.18 & 48492 & 34444 & 2813 \\
$\begin{array}{l}\text { Real-world Consumption } \\
\text { (TTW)(kWh/km) }\end{array}$ & 0.135 & 0.23 & 0.23 & 0.22 \\
\hline NEDC [17](kWh/km) & 33 & 0.155 & 0.140 & 0.170 \\
\hline Consumption increase (\%) & 5 & 48 & 64 & 29 \\
\hline Number of vehicle persons & & 40 & 22 & pool \\
\hline
\end{tabular}




\section{Conclusions}

Real-world data are important for the improvement of input data and assumptions in numerous research topics in the domain of electric vehicles. So can real-world use-related data, such as driving behaviour and frequency of use, and technological performance, such as range and energy consumptions, contribute to more accurate outcome of models or assessments. Describing the energy consumption of an electric vehicle must specify the scope of the energy supply chain too, as different research domains work on a different scope. The realworld observations show that yearly driven distance is lower than the Belgian average for the conventional vehicles and is user profile specific. It shows that average yearly driven distance for the EVs used as pool car have a significantly lower yearly driven distance than electric vehicles for personal use. It also showed that further differentiating the user profile categories has an impact on the yearly driven distance and has to be taken into account when comparing with averages of conventional vehicles. The difference between the PHEV company car yearly driven distance and the Belgian average for company cars, together with some investigated outliers in both the EV and PHEV categories, show the importance of the influence of the boundary conditions of the project (company restrictions, specific use, and available infrastructure) to the average use. Further research must be done to quantify these influences. The average real-world TTW energy consumption showed to be $30-60 \%$ higher than the values for NEDC consumption. Individual consumptions, however, vary with a number of parameters like driving style, road topology and weather and were not investigated here. Finally, as this data was generated in the living labs, it is both real-world and experimental, i.e. the data is limited by the boundaries of the project (corporate policies, user inexperience, level of instruction of the user, data completeness). Although care was exerted through filtering and aggregation, this causes a margin of error which is difficult to estimate, and thus should this data be supplemented with other additional data to confirm and refine above conclusions

\section{Acknowledgments}

The authors would like to acknowledge
- Agency for Innovation by Science and Technology in Flabders (IWT) as the funder for the $\mathrm{PhD}$ grant of the first author

- Flanders' Living Lab partners for their contribution in providing data

- Flanders Make for the support to our team.

\section{References}

[1] Coosemans T., Lebeau K., Living Labs for electric vehicles in Flanders, EVS26 proceedings, May 2012

[2] Messagie, M., Boureima, F., Coosemans, T., Macharis, C., Van Mierlo, J. (2014) A RangeBased Vehicle Life Cycle Assessment Incorporating Variability in the Environmental Assessment of Different Vehicle Technologies and Fuels. ENERGIES Volume: 7 Issue: 3 Pages: 1467-1482

[3] http://www.proeftuin-ev.be/

[4] Martin W., Pierre B., Rudolf H., et al., Analyzing on-road emissions of light-duty vehicles with Portable Emission Measurement System (PEMS), 2011, JRC scientific and Technical Reports

[5] André M., Real-world driving cycles for measuring car pollutant emissions - Part A: the ARTEMIS European driving cycles, Report June 200

[6] Schwarzer V., Ghorbani R., Drive Cycle Generation for Design optimization of Electric Vehicles, IEEE Transactions on vehicular technology, Vol.62, No1, January 2013

[7] Lee T., Synthesis of real-world driving cycles and their use for estimating PHEV energy consumption and charging opportunities: case study for Midwest/US, IEEE Transactions on vehicular technology, Vol. 60, No 9, November 2011

[8] Bishop J., Axon C., McCulloch M., A robust, datadriven methodology for real-world diving cycle development, Transportation research part D, 2012, 17, 389-397

[9] Messagie M., Boureima F., Matheys J., Sergeant N., Timmermans J.-M. Macharis C., Van Mierlo J., Environmental performance of a battery electric vehicle: A descriptive life cycle

approach, World Electr. Veh. J. 2011, 4, 782-786

[10] De Vroey L., Plug-to-wheel energy balanceResults of a two years experience behind the wheel of electric vehicles, EVS27 conference proceedings, November 2013

[11] Nordelöf, A., Messagie, M., Tillman, A., Söderman, M., Van Mierlo, J. (2014) 
Environmental impacts of hybrid, plug-in hybrid, and battery electric vehicles-what can we learn from life cycle assessment? Int J Life Cycle Assess DOI 10.1007/s11367-014-0788-0

[12] Messagie M., Lebeau K., Cossemans T., Macharis C. Van Mierlo J., Environmental and financial evaluation of passenger vehicle technologies in Belgium, Sustainability, 2013, Volume 5, pages 5020-5033

[13] Messagie, M., Mertens, J., Oliveira, L., Rangaraju, S., Sanfelix, J., Coosemans, T., Van Mierlo, J., Macharis, C. (2014) The hourly life cycle carbon footprint of electricity generation in Belgium, bringing a temporal resolution in life cycle assessment. Applied Energy Volume: 134C pp. 469-476 DOI: $10.1016 /$ j.apenergy.2014.08.071

[14] Heyvaert S., Coosemans T., Van Mierlo J., Macharis C., Electric vehicle attitudes and purchase intention: A Flemish case study., Journal of Electric and Hybrid Vehicles, submitted November 2014

[15] Lebeau P., De Cauwer C., Van Mierlo J., Macharis C., Verbeke W., Coosemans T., Conventional, hybrid or electric vehicles: what technologies for an urban distribution centre?, Modeling, Control and Optimization Technologies in Electric Drive Vehicles, Hidawi, accepted Januari 2015

[16] Lebeau K., Van Mierlo J., Lebeau P. Mairesse Olivier, Macharis C., Consumer attitudes towards battery electric vehicles: a large scale survey, Int. J. Electric and Hybrid Vehicles, Vol. 5, No. 1, 2013

[17] www.ecoscore.be, January 2015

[18] Macharis, C., De Witte, A., The typical company car user does not exist: the case of Flemish company drivers, Transport Policy, 24, pages 9198, 2012

[19] Bütler T., Winkler H., Energy consumption of batter electric vehicles, factsheet BEV measurement campaign 2012, Laboratory for internal consumption engines, April 2013

\section{Authors}

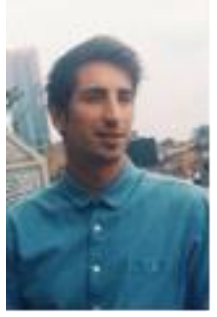

Cedric De Cauwer graduated at the Vrije Universiteit Brussel (VUB) as a mechanical engineer in June 2011. He started as a PhD student in September 2011 at the VUB, working on the SAFEDRIVE project. He has been granted a IWT $\mathrm{PhD}$ scholarship, allowing him to work on the subject of EV range estimation since January

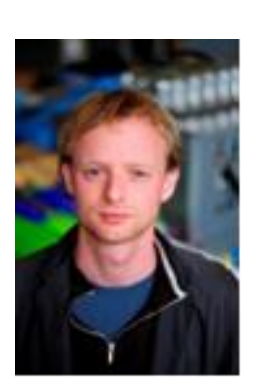

2013.

Maarten Messagie is an engineer specialized in industrial development, he also obtained a Master degree in sustainable development (VUB) and specialized himself in environmental assessment methodologies as trainee in an environmental consultancy agency and as PhD student in Aalborg University and the University of Trondheim (NTNU). Currently he is an environmental researcher for the MOBI team working on environmental assessments (Well-toWheel and Life Cycle Assessment) of the transport and energy sector in various national and international projects. His main focus is on conventional and alternative vehicles, with a special interest for electric and hybrid cars. His research interests are alternative vehicle technologies, Life Cycle Assessment methodology, ecodesign and sustainable energy systems.

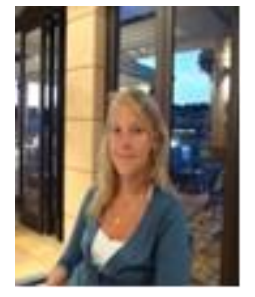

Sylvia Heyvaert acquired the degree of Master in Labor and Organizational Psychology and Master in Management. Now she is working as a researcher in the research group MOBI led by Prof. Dr. Cathy Macharis and Prof. Dr. Joeri Van Mierlo. Her $\mathrm{PhD}$ work focuses on travel and purchase behavior within the market of electric vehicles.

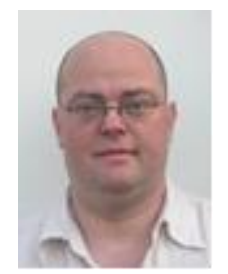

Prof. Dr. Thierry Coosemans obtained his Ph.D. in Engineering Sciences from Ghent University in 2006. After several years in the industry, he became a member of the MOBI-VUB research team on transport technology at the VUB, where he works as a scientific project manager and coordinator. His main research interests are electric and hybrid propulsion systems. He is currently involved in the FP7 projects Safedrive, Opera4FEV,SuperLIB, Smart EV-VC and the European Electro-mobility Observatory, as well as in the Flemish Living labs for Electric Vehicles. $\mathrm{He}$ is an active member of EARPA 


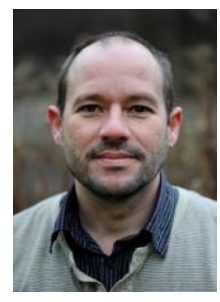

Prof. Dr. ir. Joeri Van Mierlo obtained his Ph.D. in electromechanical Engineering Sciences from the Vrije Universiteit Brussel in 2000. He is now a full-time professor at this university, where he leads the MOBI Mobility and automotive technology research centre (http://mobi.vub.ac.be).Currently his activities are devoted to the development of hybrid propulsion 